\title{
EL CONFLICTO ENTRE JUAN DE PALAFOX Y LA COMPAÑÍA DE JESÚS \\ María de Lourdes Ibarra Herrerías*
}

RESUMEN: En el proceso de secularización emprendido por la Corona española, esta se enfrentó a la difícil tarea de reducir a las órdenes regulares a la jurisdicción del Ordinario. En este contexto, tuvo lugar en la Puebla de los Ángeles, en la Nueva España, el aparatoso enfrentamiento entre el obispo Palafox y la orden ignaciana.

\author{
yode \\ THE CONFLICT BETWEEN JUAN DE PALAFOX \\ AND THE SOCIETY OF JESUS
}

ABSTRACT: During the secularization process undertaken by the Spanish crown, the difficult task of reducing the orders according to the Ordinary jurisdiction occurred. In the midst of it, a dramatic confrontation between Bishop Palafox and the Ignatian order took place in Puebla de los Angeles, New Spain.

PALABRAS CLAVE: secularización, poder, jurisdicción, privilegios, regulares.

KEY WORDS: secularization, power, conflict, jurisdiction, privileges, orders.

RECEPCIÓN: 1 de marzo de 2016.

APROBACIÓN: 3 de mayo de 2016.

* Departamento Académico de Estudios Generales, ITAM. 



\section{EL CONFLICTO ENTRE JUAN DE PALAFOX Y LA COMPAÑÍA DE JESÚS}

El enfrentamiento entre el obispo de Puebla, don Juan de Palafox y Mendoza, y la Compañía de Jesús, hoy lejano en el tiempo, pero no ajeno y siempre presente en la constante lucha por el poder a lo largo de la historia, tuvo lugar durante la década de 1640 en la Nueva España, en el marco de una confrontación mayor.

Dado el peso y la trascendencia que tuvo el acontecimiento, es necesario situarlo en un contexto más amplio, el de la búsqueda del Estado español por disminuir la fuerza y la influencia política y económica que los regulares habían alcanzado, en este caso la poderosísima Compañía de Jesús. En cierta forma, la Corona deseaba aprovechar los enfrentamientos entre las diócesis y las órdenes religiosas para controlar mejor a este vigoroso sector de la Iglesia, al que, por circunstancias especiales, en los primeros años del establecimiento del imperio español en el Nuevo Mundo había tenido que recurrir para la cristianización de los paganos que habitaban los nuevos dominios. Para ese momento, los tiempos demandaban mayor sujeción de la Iglesia misionera y, como fuese, los regulares tomaban muy a mal la idea y el proyecto de someterse al Ordinario, lo cual veían como una intromisión en sus asuntos internos y un obstáculo para cumplir con su misión.

El siglo XVII, llamado por algunos autores "de la decadencia", fue en realidad una etapa turbulenta y difícil. Lo fue para la antigua España 
y para la nueva, uno de sus territorios de ultramar. La metrópoli se encontraba inmersa en una serie de problemas que complicaban lo que se había creído que era un destino glorioso y afectaban todos los ámbitos: político, económico, social y diplomático. La llegada al trono en 1598, a la edad de 20 años, de Felipe III, joven a quien su mismo padre veía falto de autoridad y decisión y que cayó bajo la influencia del duque de Lerma, "cuyo principal interés consistía en enriquecer a su familia y mantenerse en el poder", ${ }^{1}$ no auguraba un futuro promisorio.

En lo que se refiere al aspecto internacional, España enfrentó graves conflictos que la mantuvieron en constante estado de guerra en el continente europeo.

En lo económico, los problemas agobiaban también al Estado español. La crisis económica era el resultado de varios factores, de los que uno de los más importantes era la falta de solidez de la economía hispana. En un mundo en el que se iniciaba la etapa del "gran capitalismo", España se había rezagado y no había logrado la transformación, que ya antes del descubrimiento y conquista de América había dado sus primeros pasos en la zona de Aragón y Cataluña. Países como Inglaterra y las Provincias Unidas avanzaban hacia el cambio que preparaba el advenimiento de la industrialización, pero España, confiada en sus grandes riquezas de ultramar, se alejaba cada vez más de ese camino. Se necesitaban reformas estructurales, pero la debilidad de los monarcas que la gobernaron durante ese siglo y los intereses de quienes los rodearon no permitieron que se pusieran en marcha.

A todo lo anterior se sumaban problemas internos, que contribuían a complicar el no muy esperanzador panorama. La enorme burocracia y las deudas con los banqueros pesaban en demasía sobre las gastadas arcas reales. Las flotas que venían de las Indias eran atacadas, cada vez con más frecuencia, por bucaneros, filibusteros y piratas, por lo que la riqueza proveniente de América estaba en constante riesgo y se hacía necesario fortalecer su protección con navíos de guerra, lo que encarecía las operaciones. La población económicamente productiva descendía

${ }^{1}$ John H. Elliott, La España imperial, 1469-1716, 1980, Barcelona, Vicens-Vives, p. 327 . 
de forma alarmante, debido a varias causas: las guerras europeas, la migración hacia las nuevas tierras, las epidemias y el ingreso a la vida religiosa.

A todo esto deben sumarse las rebeliones internas, como las que tuvieron lugar en Cataluña, que se estableció como república desde 1640 hasta 1652, y la de Nápoles, también durante esos años.

Los dos reyes que gobernaron de 1598 a 1665, Felipe III y Felipe IV, vieron, sin lograr hacer gran cosa para evitarlo, cómo España perdía la supremacía política y económica que había ejercido durante el siglo XVI en Europa.

\section{La Nueva España}

Setenta y nueve años habían transcurrido desde que Hernán Cortés y sus huestes, aumentadas con vastos contingentes de indígenas tlaxcaltecas, enemigos tradicionales de los mexicas, consumaron la conquista del otrora orgulloso imperio azteca y de la mayor parte de la zona mesoamericana.

El territorio de la ahora llamada Nueva España, bajo el dominio de la Corona española, se había transformado y seguía ampliándose; ciudades y pueblos de traza europea iban desplazando a los antiguos centros indígenas, quedando algunos sepultados y sirviendo como cimientos de las nuevas construcciones de piedra, o bien desaparecieron, en algunas regiones, como consecuencia del abandono al irremediable avance de la selva.

Crecía el número de caminos que permitían el paso no solo de viajeros, sino de caravanas cargadas de productos que iban o venían de la metrópoli. Se explotaban extensos campos en los que se producían los nuevos cultivos, necesarios para la dieta de los nuevos amos de la tierra, como el trigo y la cebada, y también las de exportación como la caña de azúcar, etc. Sin embargo, no solo había cambiado el paisaje, sino que la transformación social era mucho más profunda. Una realidad diferente había surgido y respondía a distintas necesidades y exigencias. A la población encontrada por los españoles se le imponían nuevas 
formas de organización social, novedosas pautas culturales y, por supuesto, una distinta concepción de la divinidad, de la vida y de la muerte. Así surgió una sociedad cada vez más compleja. Ya en la segunda parte del siglo XVI y desde luego en los inicios del XVII, es evidente que la simplicidad de la organización social de los primeros años en dos repúblicas claramente definidas, la de españoles y la de indios, no hubiera podido subsistir durante mucho tiempo. Apareció un grupo como resultado de la mezcla de estos dos originales, el de los mestizos. A estos tres pronto se sumaron los trabajadores negros traídos desde las lejanas tierras africanas.

Los mestizos, "castas y gente menuda" se encontraban diseminados por todo el territorio, tanto en las ciudades como en los pueblos y el campo, y desde luego en los minerales del norte de la colonia, a donde acudían en busca de trabajo, y de fortuna, pues no hay que perder de vista que no estaban sujetos a las rígidas leyes impuestas a la población indígena.

Ahora bien, en la república de blancos fue aumentando el número de españoles nacidos en las Indias: los criollos, orgullosos herederos de las glorias de sus antepasados, dueños de haciendas, minas y obrajes, deseosos de encontrar su lugar en el mundo, de afirmar su identidad. A ellos precisamente se dedicó gran parte de la actividad educativa de la Compañía de Jesús, y con ellos la corporación religiosa logró establecer una profunda identificación, no solo en cuanto a intereses religiosos, sino también económicos y culturales.

Hacia 1600, la población de la Nueva España se encontraba concentrada en la región central, al norte en la zona del Bajío y del Pánuco y al sur en los actuales estados de Oaxaca y Guerrero y al sureste hasta la península de Yucatán. La frontera norte era imprecisa y la alejaba constantemente la presión de la búsqueda de yacimientos de plata. Así se estableció la "ruta de la plata", que durante el primer siglo de conquista llegó hasta Santa Fe de Nuevo México. Ahí, en el norte, aparecieron los presidios militares, "cadena de fortificaciones para proteger las comunicaciones entre el centro y los minerales recién descubiertos", 2

${ }^{2}$ Peter Gerhard, La frontera norte de la Nueva España, 1996, México, UNAM, p. 46. 
y que extendió sus eslabones a todo lo largo del septentrión durante los dos siglos siguientes. Las armas acompañaron la actividad evangelizadora, emprendida principalmente por los franciscanos a partir de 1574, y por los miembros de la Compañía de Jesús en la última década del siglo XVI.

\section{La Compañía de Jesús}

En el siglo XVI culminó un largo proceso de cuestionamiento a la Iglesia, que se manifestó en el deseo de revisar asuntos de gran importancia acerca de la esencia misma de la religión y de la autoridad absoluta de Roma. Muchas habían sido las voces que, desde siglos anteriores, denunciaron el deterioro de la disciplina en el seno mismo de la institución, los excesos y la corrupción. Algunos habían encontrado respuesta a su inquietud en la fundación de nuevos institutos religiosos en los que se intentó revivir el ideal cristiano, mediante el retorno a la austeridad y a una forma de vida acorde a las enseñanzas de Cristo.

Durante el siglo XVI, el Occidente cristiano se enfrentó a una de sus crisis más graves, que lo llevó a la ruptura causada por la Reforma. Varias y no una fueron sus causas, y quizá la explicación más simple alude a la corrupción reinante, al libertinaje y a la falta de apego al ideal de vida cristiano. Pero los reformistas fueron mucho más allá y llegaron incluso al rechazo del dogma, lo que puso en tela de juicio los fundamentos mismos de la religión. Hubo también quienes, sin romper con Roma, alzaron su voz para combatir la corrupción, reforzar la esencia de la fe y evitar el desmoronamiento de la estructura eclesiástica.

El ímpetu de los reformadores, al que se sumó la decepción, la confusión y angustia de muchos fieles, no pudo ser frenado. La rebeldía fue total y bajo la guía de Martín Lutero, Calvino y otros, el rompimiento con Roma fue irremediable. La reforma protestante sacudió hasta sus cimientos el pesado edificio eclesiástico, resquebrajó en definitiva la autoridad del Papa, al que muchos ya no reconocían como sucesor de Pedro, y fracturó la unidad de la cristiandad en torno a Roma. Este hecho de tan singular importancia provocó conflictos sangrientos entre los 
pueblos, que se extendieron a la primera mitad del siglo XVII, cuando en los Tratados de Westfalia se puso fin a la cruenta y devastadora Guerra de los Treinta Años.

Después del desconcierto causado por el impacto inicial, la Iglesia romana, con el Papa Paulo III a la cabeza, emprendió una larga lucha por la reconquista del terreno perdido no solo en lo espiritual, sino también en lo político. Ello implicó una profunda reflexión interna para fortalecer sus fundamentos. Paulo III renovó la Curia y "designó una comisión episcopal encargada de redactar un informe sobre el estado de la Iglesia y de proponer una reforma. El informe de estos especialistas es un documento más terrible aún que las imprecaciones de Lutero". 3

El Concilio de Trento fue la culminación de estos esfuerzos. Sus miembros llevaron a cabo la reflexión sobre la esencia misma del dogma y decidieron los cambios necesarios para el mejor funcionamiento de la Iglesia, la preparación del clero con miras a un mayor conocimiento de los Evangelios y la enseñanza. Se percibía la voluntad de restituir la autoridad del pontífice romano y de unificar la Iglesia en torno a él.

En este contexto de ruptura espiritual de la cristiandad, de deterioro de la autoridad del sucesor de Pedro y de la necesidad de evangelizar de nueva cuenta a los fieles, surgió una nueva orden religiosa, de fuerte carácter combativo y de características más acordes al momento. Ignacio de Loyola y un pequeño grupo de seguidores fundaron la Compañía de Jesús, aprobada por el Papa en 1540, y que se extendió rápidamente no solo por Europa, sino que llegaría a las lejanas tierras del continente asiático y al vasto territorio conquistado por España y Portugal allende el Atlántico, las Indias Occidentales. En poco tiempo, los jesuitas se manifestaron como adalides de la Contrarreforma, en la lucha por recuperar a las almas ganadas por la Reforma protestante, en la conversión de gentiles y en el combate contra el turco infiel que amenazaba a Europa.

La Sociedad de Jesús, nombre que adoptó, se caracterizó por la búsqueda de soluciones prácticas y por el rompimiento con el modelo común de las reglas de vida de las demás órdenes. Se apartó de todo

${ }^{3}$ Jean Lacouture, Jesuitas. I. Los conquistadores, 1993, Barcelona, Paidós, p. 120. 
lo que pudiese estorbar su misión, que exigía preparación, fortaleza física, energía y una gran movilidad.

"Así, echaron por la borda la oración colectiva, los ayunos debilitadores, las penitencias extenuantes y hasta prescindieron de un atuendo distintivo."4 Aun antes de la aprobación de sus constituciones, el jesuita Francisco Javier partió rumbo a las Indias Orientales por deseo expreso del rey de Portugal. Otros se dirigieron a Irlanda y a regiones del Imperio Germánico, donde los “herejes”, seguidores de Lutero, aumentaban todos los días. "Después de Trento, los textos y las iniciativas de Loyola, Laínez y Canisio harán mucho para acreditar la imagen de una Compañía transformada en máquina de guerra contra el luteranismo y el calvinismo." 5

Esta orden, activa, disciplinada y novedosa en sus métodos de trabajo, que perseguía la renovación de la vida cristiana y la incorporación al cristianismo de aquellas almas que habitaban tierras lejanas, muy pronto sumó a su carácter la vocación por la enseñanza. En 1572 llegó finalmente a la Nueva España, tras varios intentos y por la intervención de personajes prominentes.

Treinta y dos años tuvieron que pasar desde que el primer jesuita, Francisco Javier, partiera hacia el Oriente para que, por petición del obispo de Michoacán Vasco de Quiroga, llegaran los jesuitas a la Nueva España. Respaldó este deseo la orden de San Francisco, que esperaba la ayuda de los ignacianos para continuar la conversión de los naturales, y el virrey, don Martín de Enríquez, el del cabildo de México y algunos españoles asentados, como el acaudalado Alonso de Villaseca, futuro gran benefactor de la orden, pues los veían como los educadores idóneos para encargarse de la formación de los españoles nacidos en las nuevas tierras, los criollos.

Eran pues dos los argumentos, el doctrinal y el educativo, los que se presentaron al padre Laínez, provincial general de la Compañía. Los jesuitas encontraron dificultades para cumplir con el primer objetivo, pues su plan era contribuir a la evangelización de los indígenas y las

${ }^{4}$ Elsa Cecilia Frost, "La crónica general jesuita", en Historia de la historiografía mexicana, en prensa, México, UNAM, p. 1.

${ }^{5}$ Lacouture, op. cit., p. 145. 
órdenes mendicantes que los habían precedido ya se habían repartido prácticamente el territorio que concentraba la mayor parte de la población aborigen. La Compañía se dirigió a zonas alejadas del centro colonial y enfocó sus esfuerzos en el norte del territorio, donde estableció un sistema de misiones en el que la población estaba constituida, según Pérez de Ribas, cronista de la orden, por "las gentes más bárbaras y fieras del nuevo orbe".

En cuanto al segundo objetivo, las cosas fueron más sencillas: los jesuitas encontraron el campo libre para trabajar entre la juventud criolla, pues "las sagradas Religiones que había en la Nueva España, estaban santísimamente ocupadas en la doctrina de una inmensidad de nuevos cristianos é hijos que en Cristo habían engendrado"6 y por ello no se habían ocupado de la enseñanza de los españoles y criollos.

Los jesuitas se convirtieron en los educadores de los hijos de los conquistadores y primeros pobladores europeos en la Nueva España, de los "españoles mexicanos". Fundaron escuelas de estudios menores, seminarios de colegiales y colegios, y al paso del tiempo se identificaron profundamente con los grupos dominantes y sectores medios de la colonia.

\section{El conflicto entre el obispo de Puebla don Juan de Palafox y la Compañía de Jesús}

En un mundo que se movía por pesos y contrapesos, en el que el poder metropolitano se ejercía a distancia, mediante un complejísimo y aleatorio sistema de nivelaciones, componendas, acomodos y ajustes; en el que la administración civil y eclesiástica se caracterizaba por el empalme y la superposición de jurisdicciones y competencias, y en el que la organización social era jerárquica, estamental y puntillosamente observante de sitios y precedencias, no podían dejar de presentarse, con mucha frecuencia, roces, fricciones y choques frontales entre grupos. Sin embargo, por graves que hayan sido los conflictos, ninguno llegó

${ }^{6}$ Andrés Pérez de Ribas, Crónica y historia religiosa de la Compañia de Jesús en la Nueva España, 1896, México, Imprenta del Sagrado Corazón de Jesús, p. 63. 
a poner verdaderamente en riesgo la estabilidad del dominio de España en los territorios ultramarinos.

Destaca entre estas disputas la que protagonizaron el representante de la autoridad episcopal en la Puebla de los Ángeles y la Compañía de Jesús, a propósito de la cual me viene a la mente lo que algunos pensadores han planteado respecto a las luchas de poder. Nietzsche, por ejemplo, afirmaba que la voluntad de ejercer el poder condicionaba la conducta. De igual manera, otros teóricos más recientes establecieron que, en el seno de las comunidades, tarde que temprano aparecen grupos o "fuerzas", cuya definición se da a partir de su capacidad para "impactar o repercutir sobre otras fuerzas". ${ }^{7}$ Lo que ambos supuestos, complementarios, significan es que el apetito del poder resulta casi connatural a la humanidad y que su ejercicio pasa por la imposición de las propias intenciones u objetivos sobre los del prójimo. Este concepto permite contextualizar, al menos parcialmente, el acontecimiento del que he de ocuparme a continuación.

No es ninguna novedad afirmar que para el siglo XVII, el poderío de la rama regular de la Iglesia novohispana estaba bien cimentado, y dentro de ella, la Compañía de Jesús era institución señera, pues, como apunta Wright, constituía ya una de las organizaciones más influyentes del reino. ${ }^{8}$ Así pues, su acción y su vertiginoso proceso expansivo tenían que toparse tarde que temprano con otros sectores y ejercer presión sobre ellos. Había poderosos intereses afectados por el desarrollo de la voluminosa y prestigiada institución ignaciana; asimismo, esta veía en dichas fuerzas adversas una amenaza para su crecimiento y futuras metas.

No es de extrañar que en esta época sobrevinieran grandes tensiones y luchas políticas derivadas de la confrontación de intereses: primero, los de la Corona, que apuntaban ya a la imposición general de una estructura parroquial ordinaria sometida a los obispos; y en segundo término, del clero regular - y, consecuentemente, de la Compañía-,

${ }^{7}$ Gilles Deleuze, Foucault, citado en Julián Sauquillo González, Michel Foucault, una filosofía de la acción, 1989, Madrid, Centro de Estudios Constitucionales, p. 347.

${ }^{8}$ Jonathan Wright, Los jesuitas. Una historia de los soldados de Dios, 2005, México, Debate, p. 62. 
que buscaba mantener su margen habitual de autonomía y libertad de acción, fuera de la injerencia diocesana.

Estas fueron las razones que en la década de 1640 enfrentaron en una violenta disputa a los jesuitas y al obispo de Puebla, Juan de Palafox y Mendoza.

Juan de Palafox y Mendoza (Navarra, 24 de junio de 1600) era hijo natural del marqués de Ariza, quien lo reconoció años después. La carrera eclesiástica de Palafox fue rápida y fulgurante: representó al marquesado paterno en las Cortes de Aragón, luego fue fiscal del Consejo de Guerra y del Consejo de Indias, más tarde visitador de las Descalzas Reales, limosnero y capellán mayor de María, hermana de Felipe IV. A partir de 1629, fue canónigo tesorero de la iglesia de Tarazona, de donde salió para hacerse cargo de la diócesis de Puebla, que le encomendó Felipe IV y de la que tomó posesión en 1640.

En la Nueva España, Palafox no solo fungió como obispo, sino que desempeñó otros altos cargos, como el de visitador general del reino, juez de residencia de tres virreyes, virrey interino de junio a noviembre de 1642 y presidente de la real audiencia, aunque renunció a ese nombramiento.

Como se sabe, y en virtud del espíritu del Regio Patronato, los obispos venían a ser no solo pastores eclesiásticos, sino auténticos funcionarios de Estado. ${ }^{9}$ A Palafox se le había elegido por su carácter, experiencia y conocimiento de los asuntos de las Indias, y su misión era "poner orden en la Nueva España y resolver pleitos ya antiguos". ${ }^{10} \mathrm{La}$ consigna y la tarea que venía a cumplir era la implantación de reformas para mejorar la formación y la disciplina del clero diocesano, pero, sobre todo, venía a establecer un control más férreo sobre la rama regular y a limitar sus antiguos privilegios. En su política estaban consideradas prioritariamente la secularización de doctrinas o curatos de indios, la normalización del pago de diezmos y la regularización de las licencias ministeriales de las corporaciones religiosas. Veamos que sucedió.

${ }^{9}$ Antonio, Rubial, La santidad controvertida. Hagiografía y conciencia criolla alrededor de los venerables no canonizados de Nueva España, 1999, México. Universidad Nacional Autónoma de México, Fondo de Cultura Económica, p. 144.

${ }^{10}$ Francisco Sánchez Castañar, Don Juan de Palafox. Virrey de la Nueva España, 1988, Madrid, Fundación Universitaria Española, p. 45. 
A un año escaso de su llegada, Palafox tuvo con la orden franciscana su primer enfrentamiento, que empezó por un tironeo a causa de las licencias de confesión y terminó con la secularización de treinta y cuatro curatos de la diócesis. Aunque este hecho no afectó a todas las corporaciones, propició un clima general de intranquilidad y tensión entre ellas y la mitra.

Poco después, Palafox intervino en un problema entre el cabildo catedralicio y la Compañía de Jesús, que se había suscitado por una donación que el doctor Hernando de la Serna, racionero de la catedral poblana, había hecho para fundar un colegio jesuita en la ciudad de Veracruz. Sin embargo, ni de la Serna ni los ignacianos habían tenido presente o acatado la norma de cubrir el diezmo respectivo a la catedral de la diócesis. Pese a que se había advertido al racionero del riesgo en que incurría de ser excomulgado y sufrir el embargo de sus bienes, aquel perseveró en hacer la donación (1642) sin cubrir el impuesto. En consecuencia, sus bienes se embargaron para asegurar el pago y a él se le puso en prisión. Naturalmente, los jesuitas salieron de inmediato a la defensa de su benefactor, invocando ante el obispo los privilegios pontificios que eximían a la orden del pago del impuesto eclesiástico.

Si bien la actitud primera de Palafox en cuanto a este caso había sido conciliadora, pronto endureció sus puntos de vista, pues ya en 1641 había redactado un memorial sobre los diezmos que la Compañía de Jesús tildó de "falto a la verdad e injurioso", según lo expresó el cronista Pérez de Ribas.

La Compañía había solicitado que se levantasen los castigos al racionero de la catedral, a lo que el prelado poblano se negó rotundamente. Para entonces, sus decisiones tenían fuerza de autoridad, pues por la destitución del marqués de Villena, el obispo fue elevado en 1642 a la dignidad de virrey de la Nueva España.

De 1644 a los primeros meses de 1646 guardaron la calma los contendientes. Quizá haya tenido que ver el hecho de que en 1644 se designó provincial jesuita a Juan de Bueras, "persona pacífica y competente". En esta etapa, Palafox incluso recurrió a los hijos de San Ignacio para que predicaran en misiones populares del obispado. Sin embargo, no había cambiado su opinión respecto de los diezmos. 
A la muerte de Bueras ascendió al cargo un criollo de origen aristocrático, el padre Pedro de Velasco, "políticamente afín a Francisco Calderón, Andrés Pérez de Ribas y Juan de San Miguel, que capitaneaban el ala antipalafoxiana". ${ }^{11}$ Esta circunstancia encendió nuevamente los enconos en la primavera de 1646. Finalmente, el miércoles de ceniza de 1647, los ánimos se exaltaron y estalló el conflicto.

Como en el caso anterior de los franciscanos, el motivo fue la exigencia del prelado a los regulares de que presentasen las licencias para confesar y predicar, a lo que los jesuitas se negaron.

A partir de ese momento, las posturas se polarizaron: los jesuitas ignoraron la prohibición de ejercer la prédica y la confesión, sin presentar las debidas licencias al Ordinario, y el obispo respondió de inmediato con la excomunión a todo aquel que se confesara con los jesuitas o escuchara sus sermones.

Inevitablemente, esta tensión salió a las calles y creció como la espuma: aparecieron volantes, cartas, insultos, dimes y diretes, y la inquietud se adueñó de los habitantes de la ciudad. Entre tanto, el obispo, haciendo caso omiso del revuelo, continúo tranquilamente con sus actividades. En la capital, el nuevo virrey conde de Salvatierra, a quien el obispo consideraba "muy amigo" de los jesuitas, se sumó al bando de la Compañía. Según los partidarios de Palafox, este apoyo les había costado a los ignacianos unos "10 000 reales".

Ante la gravedad de la situación, el virrey pidió calma al obispo y actitudes conciliadoras, y acto seguido organizó una reunión de avenencia. Sin embargo, el 17 de junio, el obispo abandonó la ciudad de Puebla con destino desconocido.

Ya sin Palafox en la escena y sintiéndose más seguros, los jesuitas presentaron sus licencias e incluso obtuvieron algunas nuevas para quienes no las tenían. Aparentemente, se había restablecido el orden, pero en el fondo el ambiente contencioso no había desaparecido: tanto en México como en Puebla los ignacianos y sus adeptos festejaron su triunfo, llenando de improperios al obispo. Palafox, desde su refugio,

${ }^{11}$ Jonathan Israel, Razas, clases sociales y vida política en el México colonial, 1600-1670, 1989, México, Fondo de Cultura Económica, trad. de Roberto Gómez Ciriza, p. 231. 
escribía cartas a sus partidarios, que eran distribuidas por los carmelitas, que nunca dejaron de respaldarlo.

Finalmente, el obispo decidió terminar con su destierro y regresar a la ciudad de los Ángeles. Para permitirle el regreso, el virrey le exigió que se sometiera a su autoridad y aceptara ciertas condiciones. E1 25 noviembre de 1647, Juan de Palafox y Mendoza volvió a tomar posesión de su cargo, aunque fue destituido como visitador del reino.

Estando en este punto la situación, se hizo público un breve de Inocencio $\mathrm{X}$ favorable al obispo. En el documento se anulaba "el privilegio de los jesuitas", pero no se hacía referencia a los límites que Urbano VIII había puesto al privilegio de Gregorio IV, que exceptuaba de la norma a los institutos religiosos de las posesiones españolas. Esta omisión fue capitalizada por los jesuitas para formular reclamaciones. ${ }^{12}$

Ante la magnitud del escándalo y las graves consecuencias que había causado en la Nueva España, en 1648 el rey dirigió sendas cédulas a los principales protagonistas: Palafox; el arzobispo de México, Sáenz de Mañozca; los jesuitas, la Audiencia y otros. En ellas, los instaba a actuar con prudencia y también condenaba ciertas actitudes, como las del padre Velasco o las del arzobispo, que, lejos de contribuir a la pacificación de los ánimos, los habían exacerbado.

Ese mismo año, y para suprimir del escenario a dos de los principales protagonistas, Felipe IV dispuso el traslado del virrey Salvatierra al Perú y el regreso de Palafox a España, a lo que se sumó la postura de la máxima autoridad de la Compañía desde Roma, el padre Vicente Caraffa, quien después de conocer por boca del padre Lorenzo de Alvarado los sucesos, remitió una carta de amonestación (30 de enero de 1648) al provincial Velasco.

Finalmente, en mayo de 1649, Palafox partió rumbo a España. Desde Veracruz respondió a los cargos que se le habían formulado. Sin embargo, la salida del prelado de la diócesis poblana, que los jesuitas vieron como muestra de triunfo, no zanjó todas las diferencias. Los partidarios de Palafox y los de los jesuitas (e incluso estos mismos) siguieron atacán-

${ }^{12}$ Gregorio Bartolomé, Jaque mate al obispo-virrey. Siglo y medio de sátiras y libelos contra don Juan de Palafox y Mendoza, 1991, México, Madrid, Buenos Aires, Fondo de Cultura Económica, p. 31. 
dose, hasta que, en 1653, Inocencio X ordenó la imposición de "perpetuo silencio sobre el pleito", y el 20 de mayo, tras laboriosas negociaciones, se suscribió un documento en Madrid que asentaba oficialmente la concordia entre Palafox y la Compañía. "Aparentemente, el obispo estampó su firma un tanto a disgusto, pero tanto él como los ignacianos se comprometieron a acatar las disposiciones papales y a mostrarse mutuo reconocimiento." $" 13$

Se sabe que Palafox anhelaba volver a la Nueva España, a su diócesis de Puebla; pero el rey no condescendió, sino que lo retuvo en la península como obispo de Osma (Soria), cargo que ocupó hasta su muerte en 1659.

\section{Opiniones encontradas}

A partir de la abundante documentación directa que acumuló este sonadísimo pleito, no resulta muy difícil definir las posiciones que asumieron sus distintos protagonistas: el obispo Palafox, la Compañía, el virrey, la Audiencia, los procuradores, etc. Podemos afirmar que "el formidable enfrentamiento entre Palafox y la Compañía en México, ni se dio en campo neutral, ni se desarrolló en clima neutral, ni fue analizado por jueces neutrales". ${ }^{14}$

En efecto, no hubo objetividad: metidos de lleno en el fragor de la batalla, para los contendientes todo se reducía a un prurito de orgullo, a un echar pulsos para ver quién se salía con la suya. Los jesuitas de la provincia de México veían en Palafox a la personificación de la tiranía, la soberbia y el abuso de autoridad que no paraba en respetos ni consideraciones. El obispo, por su lado, pensaba que la Compañía, engreída a causa de su poder económico, sus influencias políticas y sus amplias libertades y prerrogativas, era una corporación absolutamente díscola e insubordinada. Uno y otros se echaban en cara las mismas faltas y errores y su visión de los hechos estaba muy distorsionada, por la gran carga de emotividad y el antagonismo de todos. En sus acalorados y

${ }^{13}$ Ibid., p. 36.

${ }^{14}$ Ibid., p. 12. 
parciales testimonios, tanto los jesuitas como el obispo querían legitimar a toda costa sus respectivas causas y también presentarse como víctimas del rival.

Más allá de las versiones maniqueas de los protagonistas, lo que en realidad se estaba dirimiendo era la total reestructuración del aparato eclesiástico en América. Al inicio de la empresa colonizadora, la Corona se había servido del brazo regular de la Iglesia para llevar a cabo la conversión de los naturales. La disponibilidad y preparación del clero regular, así como los privilegios pontificios obtenidos (como exenciones de pagos de diezmos, realización de funciones reservadas al episcopado, etc.), le habían conferido un auténtico régimen de excepción y le habían permitido prosperar y crecer hasta hacerse una organización poderosa en sus distintas corporaciones.

A la vuelta de cien años, las cosas eran muy distintas. La metrópoli quería normalizar su Iglesia indiana, restablecer el orden "natural", de suerte que los regulares se reintegraran a las ocupaciones propias de su vocación, que eran la vida claustral en las ciudades o la actividad misional en zonas de infieles.

Como visitador y obispo, Palafox vino con la difícil consigna de limitar la enorme autonomía y las incontables prerrogativas que - en contra de las disposiciones conciliares tridentinas y de los intereses regios - disfrutaban los religiosos. Naturalmente, la aplicación de tales reformas tocaba en lo vivo a estos institutos y levantaba ámpulas de resentimiento y resistencia.

El primer punto clave de la controversia fue la cuestión de los diezmos. La Compañía de Jesús (como la orden agustina y, en menor medida, la dominica), era propietaria de fincas y haciendas agropecuarias, cuyos productos, según las nuevas políticas, debían gravarse ya con el impuesto eclesiástico. En el Memorial de Palafox se exponía la necesidad de recuperar esos ingresos para las "catedrales". Desde luego, los ignacianos no estaban dispuestos a trocar el régimen especial que habían disfrutado largo tiempo, y para el efecto, aducían dos argumentos: uno, los privilegios pontificios que amparaban su "excepción" y dos, la utilidad pública que se derivaba de ello. 
De lo primero, el alegato de la Compañía se sustentaba en que la autoridad pontificia está por encima de la de cualquier prelado; así pues, si los papas habían conferido " muy en especial á la Compañía, el privilegio de no pagar diezmos de las haciendas que poseyesen", ${ }^{15}$ resultaría "temeraria osadía" por parte de un obispo, por poderoso que fuese, poner en tela de juicio y cuestionar el derecho de los sucesores de Pedro a distribuir los bienes de la Iglesia como mejor conviniese a la institución. En particular, esta prerrogativa, lejos de ser utilizada para el enriquecimiento de la orden, representaba la única vía para mantener con vida a las misiones y los colegios, cruciales para la propagación del Evangelio por el reino y para la formación de la juventud novohispana.

La segunda de las grandes cuestiones que estaba en juego era la administración parroquial. Las doctrinas o "curatos de indios", así como algunas parroquias ordinarias que atendían las distintas órdenes religiosas, eran objeto de la atención de la Corona y del cuerpo episcopal, que esperaban transferirlas a manos de clérigos seculares.

Así pues, el trasfondo del aparatoso enfrentamiento entre el obispo y la Compañía se fincaba en algo más que la sola actitud rebelde de los jesuitas de cumplir con el requisito de presentar las licencias para su ejercicio ministerial.

Sin embargo, fue el pretexto que desencadenó la "guerra campal y abierta" con la cual el obispo quiso reformar la jurisdicción eclesiástica. Naturalmente, los regulares, y muy en especial los jesuitas, se resistieron.

Si la Compañía no resultó afectada por la secularización de doctrinas en la diócesis de Puebla, fue simplemente porque no tenía ninguna ahí. Sin embargo, sí corría un riesgo en sus fundaciones norteñas, las misiones.

Igualmente se ha dicho ya que la intransigencia, la falta de ecuanimidad de los contendientes llevó las cosas hasta proporciones y extremos inéditos, tanto así, que desde Europa llegaron las reprimendas de las autoridades. Felipe IV pidió a Palafox "que suspendiera las querellas presentadas en Roma y tratase con amor a las religiones", ${ }^{16}$ y por su

${ }^{15}$ Pérez de Ribas, Crónica, L.4, cap. XXIII, p.155.

${ }^{16}$ Bartolomé, op. cit., p. 11. 
parte, el general de la Compañía le echó en cara al provincial Velasco no haber "sabido atajar con prudencia"17 el problema.

Por mucho que las instancias superiores, en Madrid y Roma, hubieran tomado cartas en el asunto, es seguro que no alcanzaron a comprender cabalmente la complejidad y la pasión que se habían mezclado en un problema que sacudió hasta sus cimientos a la sociedad novohispana, especialmente en Puebla. Y aunque nunca estuvo en peligro la soberanía de la Corona ni la sujeción del reino, es innegable que, para una comunidad cuya estructura y vida diaria estaban, en cierto modo, condicionadas por la religión, el choque entre dos de sus principales representantes no podía dejar de ser causa de confusión y escándalo.

Como se sabe, andando el tiempo, la institución episcopal recibió cada vez más apoyo regio, en tanto que el clero regular fue perdiendo terreno. En el siglo XVIII, la política secularizadora avanzó a pasos agigantados, y en lo tocante a la Compañía de Jesús, Carlos III le asestó el golpe definitivo al extrañarla de sus dominios. Por aquel entonces se reavivó el asunto Palafox. Sin embargo, en la época que me ocupa (mediados del XVII) es muy probable que la fuerza de los hechos haya mostrado a las autoridades metropolitanas que no era todavía el momento idóneo para que el clero secular monopolizara el control parroquial y para que se recluyera a las órdenes religiosas en el pacífico silencio de sus muros conventuales; así que, con unas cuantas secularizaciones y un estruendoso pleito, terminó el problema por un tiempo.

${ }^{17}$ Sánchez Castañar, op. cit., p.115. 
